\title{
A pedagogy of critical hope in South African Higher Education
}

Vivienne Bozalek, Ronelle Carolissen and Brenda Leibowitz

\section{Introduction}

Critical hope may be viewed as an appropriate antidote and action-oriented response to conditions of inequality. In this chapter, we build on the previous two contributions in which Zembylas and Boler outline their notions of critical and naïve hope. Here we explore possible avenues through which critical hope may be achieved in educational practice.

In Chapters One and Two, Zembylas and Boler portray critical hope as an acknowledgement of the unjust and unequal societies in which we live, where privilege comes at the expense of other's abilities. They show how critical hope requires an analysis of the implications of how historical and material conditions have led us to our present positions. As Boler in Chapter Two points out, '[c]ritical hope directly challenges inscribed habits of emotional attention and signifies a willingness to exist within ambiguity and uncertainty' - this willingness includes changing our relationships with others with compassionate responsibility. Naïve hope, on the other hand, is what Boler regards as 'platitudes that directly serve the hegemonic interest of maintaining the status quo including the rhetoric of individualism; beliefs in equal opportunity; the puritanical faith that hard work inevitably leads to success; and that everyone is the same underneath the skin.' As Zembylas notes, it is important to distinguish naïve hope - which is blindly optimistic - from critical hope - which calls on us to be reflexive and so leads to transformative action. Thus, we argue that in order to achieve critical hope rather than naïve hope, ongoing dialogue and reflexivity are a necessary part of educational practice to address what Boler refers to as 'inscribed habits of emotional inattention', by which she means embedded, cultural habits of seeing. It is also important to realize that dialogue and reflexivity may also unleash further despair, however well intentioned the educators might be. In this chapter, we examine the potential of dialogue and reflexivity through an example of a teaching and learning project. Through this initiative we aimed to foster critical hope in students in higher education in a continuingly divided socio-political and material South African context. We begin by describing aspects of South African higher education in brief, before describing the setting in which this study took place.

Apartheid-designed segregated higher education institutions continue to have a major influence on students and higher educators in South Africa. In spite of formal desegregation, an informal spatial segregation, both between and within institutions, remains in South African higher education (Durrheim 2005; Erasmus 2006; Walker 2005). Furthermore, despite nineteen years of democracy since the formal demise of 
apartheid in 1994, enormous disparities still persist within the South African education system, which includes the higher education sector (Bozalek and Boughey 2012). Historically white or advantaged institutions (HWIs or HAIs) continue to be the locations of choice for privileged middle class students who have had access to high schools that are likely to prepare them adequately for higher education. These social and economic disparities, as well as the social separation between these differently placed institutions, are exacerbated by the paucity of examples of good curriculum and teaching practice at higher education level (McKinney 2004, 2007; Leibowitz 2012). Higher educators themselves are burdened by their own histories and prior experiences which influence their ability and preparedness to mediate dialogue on difference (Jansen 2009). Thus, the degree to which higher education institutions, their social make-up, ethos as well as curricula can contribute to social transformation of the sector and, more broadly, to society has been disappointing, as noted in the Ministerial Committee on Transformation and Social Cohesion (2008). This disappointment is rendered poignant by the expectations of what higher education should be able to contribute towards the transformation of South African society via its graduates and academics. This vision as expressed in the Education White Paper of 1997, for example, proposes that higher education should contribute to 'the socialisation of enlightened, responsible and constructively critical citizens'.

It is within this context that we initiated a project that attempted to engage students at two higher education institutions (HEIs) in the Western Cape, South Africa. These two institutions reflect key aspects of the divisions and inequalities typifying higher education in South Africa. Stellenbosch University (SU) is a historically advantaged or historically white institution, one of the top 'research-led' institutions in the country, with a majority of white and middle class students and academic staff. It also has a history of support for apartheid in previous decades and is struggling hard at present to transform itself socially, culturally and in terms of its curriculum (see van Rinsum's chapter in this volume for a more elaborate discussion of the history of Stellenbosch University and its current emphasis on hope). The University of the Western Cape (UWC) is a historically disadvantaged or black institution, with a majority of black and working class students. It has a history of anti-apartheid activism and in the present era is regarded as an 'engaged institution,' which still attracts poor students, and is simultaneously building its research profile. Both of these institutions, as different as they may be, are grappling with how to develop new and contextually relevant identities for themselves. Both refer to the notion of 'hope' in their institutional mission or vision statements, promotional literature and in senior executive talk and both stress the importance of social relevance and community engagement (Hope as Guiding Concept for Stellenbosch University 2011; HOPE Project: n.d.; University of the Western Cape website) We believe, however, that hope may remain at a rhetorical level unless specific institutional practices are altered, particularly those which pertain to teaching and learning and research. In order to develop a different model of teaching and learning, we conceptualized a 
project across these two institutions, which required students and academics to engage with difference across numerous boundaries.

\section{The Pedagogy of Discomfort}

The initiative on which this study is based drew on the notion of a 'pedagogy of discomfort' developed by Boler and Zembylas (2003) as a useful framework for understanding, teaching and learning about difference. This pedagogy invites students to critique their deeply held assumptions, and to destabilize their views of themselves and their worlds. The process is both painful, but contains the promise of hope for the future (Halabi 2004) by virtue of the opportunity to reconstruct previously held views and, by doing so, to move to new insights and dispositions. The 'discomfort' within this pedagogy impacts upon all members of a group, whether these are members of dominant or marginalized groups. Boler and Zembylas (2003: 115) note that 'no one escapes hegemony'. From this perspective, those positioned as dominant may be more uncomfortable discussing discrimination or oppression than marginalized groups. However, there are moments in which this is uncomfortable for individuals from any identity position, as all are impacted by dominant discourses.

Emotions are central to the pedagogy of discomfort and are conceptualized not as individualized or psychologized, but as relational and political (Zembylas 2007, 2008, 2010). Zembylas (2008: 3) writes that:

the politics of affects and emotions matters in many aspects of social life, including education [...] affects and emotions show us how power relations shape inclusion and exclusion boundaries between bodies - who should be on the inside and who should be outside.

The pedagogy also includes a moral dimension (Boler 1999) which calls upon students to 'take responsibility' (Boler and Zembylas 2003: 108). Taking responsibility is also described in relational terms: 'Taking responsibility for oneself, in this sense, involves acknowledging our situatedness and location, material, historical, and bodily specificity, the interconnections between our own well-being and the existence of others.' Students may not develop a reflexive positioning unless the process is actively facilitated by educators. The curriculum itself needs to provide opportunities for students to develop ways of seeing which are different from those provided by dominant discourses. Educators also need to ensure that the curriculum provides open and critical spaces for students to engage relationally. Taking responsibility for their own positionality and stances to knowledge requires learners to have a sense of their own agency. However, agency is intimately linked with larger material and structural forces which influences one's learning (Walker 2005). According to Norton:

The question 'Who am I?' cannot be understood apart from the question 'What am I allowed to do?' And the question 'What am I allowed to do?' cannot be 
understood apart from material conditions that structure opportunities for the realization of desires. (Norton 2000: 8-9)

Thus, questions of identity and agency are influenced by broader economic, cultural and socio-political forces that shape our society. For this reason, our view of a 'pedagogy of discomfort' is influenced by Fraser's $(2008,2009)$ trivalent view of social justice, which foregrounds three different dimensions: the economic, cultural and political spheres. All of these dimensions would require social arrangements to be in place for participatory parity or interaction as social equals to occur. This would require simultaneous attention to a recognition of the attributes of all students, an equitable distribution of resources and equal political representation. This theoretical stance is valuable in that it provides educators and students with conceptual tools to reflect meaningfully on the educational process with specific reference to difference and social justice. This view calls on educators to strive towards participatory parity in the classroom by being mindful of the way in which a learning opportunity is structured and the way resources are allocated in a course. It serves a cautionary function, in reminding educators that there are larger material and structural forces in society, which influence the final outcome of what students may take away from a learning opportunity.

\section{The Community, Self and Identity Project}

The course began with educators from both institutions feeling frustrated with conditions in our institutions. We hoped to explore ways to connect with others who wanted to achieve change with regard to teaching and learning and to work collaboratively across institutions, disciplines and social identities. The research team comprised six educators from the disciplines of social work, occupational therapy, psychology and teaching and learning in higher education (for more information about the team and its aspirations, see Leibowitz et al. 2012). We shared concerns regarding the cultural encapsulation perpetuated by the separation across historically advantaged and disadvantaged institutions. We set out to develop strategies in the curriculum that would allow students and higher educators to reevaluate their own positions in relation to implicit and explicit disciplinary knowledge, institutional and social identities. We ourselves needed to develop our own skills and dispositions in order to exercise the kind of pedagogic expertise and leadership required to develop meaningful dialogue across difference - what Burbules (2006) refers to as a 'third space dialogue' - and to forge a curriculum that crosses boundaries of social identities, discipline and institution. In doing this, we were creating different learning spaces in which we as educators and the students may have the opportunities to engage in dialogue and reflexivity as a catalyst for critical hope.

The Community, Self and Identity (CSI) course was conceptualized as one in which students and higher educators from historically differently placed institutions and disciplines would work together to critically interrogate concepts that could be 
regarded as core to human service professionals. Key to the course objectives was for students to learn together across the boundaries of race and social class, institution and discipline. We believed that this was essential in order to foster critical hope. Learning in isolated bubbles would not grant students the opportunity to test their own epistemological and ontological assumptions in relation to those with differing life experiences and disciplinary backgrounds. Herein lay the challenge: to work with appropriate levels of comfort/discomfort, depth and intensity. To engage with difference in a superficial or simplistic manner could encourage at best, false optimism, and at worst, despair. Jones, for instance, writes from the Australian perspective:

It is undeniably the case that fantasies and acts of shared communication are preferable to fantasies and acts of ignorance and separation. However, desires for shared communication must be mediated more by cautious critique and limited expectations than by urgent and ultimately self-defeating optimism.

(Jones 2005: 66-7)

Also from the Australian context, Sonn (2008: 164) writes about the challenges of engaging students on issues of difference: 'This process is not necessarily smooth and unproblematic, and while students do become aware of whiteness and the heterogeneity of whiteness, they also struggle to know its workings and often reengage in oppressive relations. Other dangers inherent in diversity work with students are that it can lead to resistance and defensiveness, as has been pointed out in the South African context (McKinney 2004, 2007). Diversity work can also further silence the marginalized, as highlighted in the context of the USA (Blackwell 2010). Burbules (2006) warns against unmediated spaces for dialogue that unwittingly disadvantage some and advantage others, and place heavy burdens on participants to manage the reciprocal interaction. Leonardo and Porter (2010) challenge the idea of a 'safe space' in public dialogue about race, pointing out how black students' views are silenced in dialogues on diversity, as they are fearful of genuinely expressing what they feel - therefore a safe space cannot be assumed. We thus need to see the classroom as a place of potential discomfort rather than necessarily a safe space.

In order to develop the possibility for a structured interchange to encourage students to engage in a pedagogy of discomfort, we needed to find techniques which would require emotional as well as cognitive labor to negotiate issues of difference. We thus looked for methods which could cumulatively create what Burbules refers to as 'third space dialogues.' These dialogues are those:

[w]hich are problematic and problematizing moments, risky and as prone to chaos or even heightened conflict, as to producing new understandings. [...] where contending parties meet - and sometimes are also linked to specific practices, even rituals, that establish an unusual place and time. (Burbules, 2006: 114) 
We anticipated that our chosen methods would lead to this kind of space and to new understandings as well as emotional engagement. Furthermore, the methods used in the project were intended to enable students to share their lived political, social and economic experiences and to challenge taken for granted knowledge in relation to the concepts of community, self and identity. Such methods included participatory learning and action and narrative techniques, blended learning and the use of guest speakers and literature which presented notions of identity as complex, fluid and non-essentialized (for more details regarding these methods see the article on the pedagogy of hope by Carolissen et al. 2010 and Bozalek and Biersteker 2011).

A range of participatory techniques, blended learning, critical reading, theatre, art, film, workshops and presentations were used to support students to explore their own, and their colleagues' personal, social and professional identities. Although the course was evaluated, reflected on and adapted after each year, the following basic structure was followed every year: there were three face-to-face workshops, interspersed with a number of online or virtual interactive exercises over a period of seven weeks.

Table 3.1 illustrates the demographic distribution of students who completed the course between 2006 and 2008 .

\begin{tabular}{|l|l|l|l|l|l|l|}
\hline & Year & $\mathbf{2 0 0 6}$ & $\mathbf{2 0 0} 7$ & $\mathbf{2 0 0 8}$ & Total & \% \\
\hline Discipline & Psychology & 41 & 14 & 13 & 68 & 24.1 \\
\hline & Social Work & 50 & 44 & 54 & 148 & 52.5 \\
\hline & Occupational Therapy & N/A & 44 & 22 & 66 & 23.4 \\
\hline Gender & Female & 78 & 93 & 77 & 248 & 87.9 \\
\hline & Male & 13 & 9 & 12 & 34 & 12.1 \\
\hline Racei & African & 19 & 30 & 36 & 85 & 30.1 \\
\hline & Coloured & 43 & 58 & 35 & 136 & 48.2 \\
\hline & White & 29 & 14 & 6 & 49 & 17.4 \\
\hline & Indian & - & - & 2 & 2 & 0.7 \\
\hline & Not specified & - & - & 10 & 10 & 3.6 \\
\hline Language & African & 17 & 30 & 30 & 77 & 27.3 \\
\hline & Afrikaans & 46 & 22 & 16 & 84 & 29.8 \\
\hline & English & 28 & 50 & 41 & 119 & 42.2 \\
\hline
\end{tabular}




\begin{tabular}{|l|l|l|l|l|l|l|}
\hline & Other & o & o & 3 & 3 & 1.1 \\
\hline Total & & 91 & 102 & 89 & 282 & - \\
\hline
\end{tabular}

Each course started with the first face-to-face workshop at UWC. Approximately 95 students from SU and UWC took part on an annual basis, incorporating the disciplines of Social Work, Psychology and Occupational Therapy. At the initial workshop, students were allocated to groups comprising six students from the different institutions and disciplines. A facilitator from one of these disciplines or a course designer was assigned to work with a particular small group for the duration of the course. The course began with an introduction to Participatory Learning and Action (PLA) techniques. PLA techniques are group-based, open-ended, flexible visual methods that are used in the learning process (Bozalek and Biersteker 2010; Chambers 2007). The specific PLA techniques that we utilized were community mapping and rivers of life.

For the community mapping exercise, students were asked to draw a picture/map of their homes and neighborhoods including the resources that they identified as being available. They were then asked to identify and label three things that they wished to change (which were identified as being physical or related to attitudes and/or social issues). Finally, they were asked to prioritize these issues and rank them from most to least important. After the drawing and ranking exercise they were requested to explain their pictures and the identified changes they wished to make in their environments with other members of their small groups.

The second PLA technique employed was the river of life. In this exercise students drew the rivers of their lives that had brought them to their current choice of profession/discipline. They examined different periods in their lives, by going back to the source of the river (their early years). Students could use structural aspects of rivers such as ebbs and flows to symbolize quiet, peaceful times (smooth flow) or wild, difficult times (waterfalls, rough water). They introduced detail such as tributaries and different colours to illustrate important events and moods, which impacted on their lives.

We chose to use these PLA techniques for a number of reasons. Firstly, they provided an excellent visual medium for differently positioned students across institutions to introduce themselves to each other. The techniques mediated an in-depth and meaningful interaction around student experiences of community, self and identity. The drawings - and discussion which ensued - ensured a powerful means of eliciting self depictions and perceptions of privilege and disadvantage. The third reason for using these techniques was that students across the institutions and disciplines were differently placed in relation to academic discourses, and the visual medium provided a way of leveling the playing fields and valuing subjugated knowledge. In this way, we designed the curriculum so that students who had had less access to 
traditional academic resources would be able to contribute confidently to the debates (Bozalek and Biersteker 2010). Finally, these techniques provide channels for engaging emotionally with issues of difference, whilst simultaneously enabling participants to distance themselves from their experiences depicted in the drawings.

The drawings were photographed and uploaded onto an e-learning platform. In the virtual space, students could see only the work of those students in their own groups. This facility provided an opportunity for further virtual interaction within small groups around issues of community, self and identity. At this stage, critical literature was introduced to facilitate further interrogation of their initial communication around these concepts.

After engaging with each other and the literature in a series of online activities, students met for a second face-to-face workshop at UWC. During this second workshop, various guest speakers were asked to reflect on their experiences of community, self and identity. Guest speakers included Berni Searle, an acclaimed South African artist, who through her video installations explores issues of racialized, gendered and classed identities. The Remix theatre group of differently able-bodied dancers was another example of performance related to difference to which the students were exposed. Students also were given the opportunity to work in their small groups to prepare presentations of their own understandings of community, self and identity for the third face-to-face workshop held at SU. At this workshop, students presented their work in their small groups to an audience of their peers, facilitators and invited guests. This was the final encounter which the students had with each other. At this workshop the course was evaluated by the students. The final online assignment that was required was an integrative essay reflecting on how the readings influenced their learning experiences in the course. They specifically had to think about how the readings, in conjunction with their experiences, impacted on their understanding of notions of 'community, 'self' and 'identity.' Finally, they wrote a reflective essay in which they considered whether their learning in this course differed from previous learning about notions of community, self and identity.

\section{Student Responses}

Although $97 \%$ of the students each year reported that they appreciated the course, an analysis of the reflective essays written by students in the 2006 course revealed that the teaching methodology we employed was successful in providing an opportunity for all students to engage with issues of difference.

An analysis of student reflective essays revealed that engaging in a pedagogy of discomfort requires a cognitive as well as an affective dimension. The cognitive dimension involved working with the prescribed texts and with concepts about society and the past, which are salient in the South African post-apartheid public discourse: 
When I think of my previous notions of community, I thought of a community being a unit working together to bring about positive change (ubuntu). This view remains the same only now I understand the other face of community. I discovered, while working with others in my group that people's views are really different. I now see the negative political side of the notion as depicted in the atrocities committed in the past, in the name of community building.

(Samanthaii, SU) (Quoted in Leibowitz et al. 2010: 90)

The affective dimension involves moments of gratification and resolution as well as moments of despair, fear and anger. The affective dimension was noted in student accounts; for example Carl, a white student at SU, described his experience as one of "cognitive dissonance," where the "emotional fire inside me cannot be contained" (quoted in Leibowitz et al. 2010: 89).

Although all students learnt something, for many, the learning remained at a superficial level while, for others, the learning was deep and engaged (Leibowitz et al. 2010). How much students learnt depended partly on their prior learning and experience. We found via a longitudinal study conducted for the project that for some of the students who participated in the course, it had a deep and lasting impression and informed their reflective engagement with their professional work after they had graduated (Carolissen 2012):

I thought a lot about my identity and what had shaped it and I thought a lot about Apartheid and its impact on me and other students. I do find myself often thinking about space and how that affects so much of who we are and how we experience life and opportunities. I work with people and individually [...] and understanding their community where they are coming from, their different cultures, beliefs and their values it just makes my work easy, helpful and valuable to all my clients. And it also gives me my identity as I know where I belong as well as learning to accept people individually.

(Google group 2, UWC, participant 2, occupational therapy, female, 2008)

(Quoted in Carolissen 2012: 68)

There were many instances of students seeming to develop a sense of reflexivity and agency through the course, as one of the students wrote in her reflective essay towards the end of the course. Samantha, a coloured student, was in a minority in the school she had attended and in a minority in the predominantly white university that she was attending:

Through all of this, my identity finally touched base. Honestly speaking, I was going through a bit of an identity crisis. Because I am 'coloured' I always felt that we did not have a set culture, I found myself sometimes adapting to things I did not want to do, just so that I could fit in [...] This collaboration provided the 
opportunity to combat the negative internalisations that existed in me due to what was installed in me.

(Samanthaii, SU)

(Quoted in Leibowitz et al. 2010: 89)

According to Halabi (2004: 8), dialogue 'between groups is painful, because it involves letting go of a familiar situation and a stable, clear reality, however dreadful; but it is also full of hope for a better future.' The process students were required to undergo involved learning as well as unlearning:

For the first time in my life, I was the so-called 'odd one out', since I was the only white girl and I also come from a more privileged background than the other group members. I think that maybe the most valuable lesson that I have learnt is the feeling of the possibility of rejection and 'standing out'. It is important to note that my group members' reactions and behaviour honestly did not contribute to this experience, but even so I felt that my appearance and background separates me from them and that they look at me as an outsider [...] As a community psychologist I will often work with races other than my own and therefore this is an important realization for me for my future work.

(Alan, SU)

(Quoted in Leibowitz et al. 2010: 90)

As Leonardo and Porter (2010) note, it is important to work through rather than avoid the discomfort associated with the dialogue around issues of difference. Thus the route towards a critical hope is an ongoing and cyclical process of dialogue leading to disruption, reflexivity, and possible reconfiguration of previously held positions. It is also one which might involve elements of despair along the way. When reflecting on one's positionality regarding privilege and discrimination, despair might appear to be a legitimate and necessary response. Obviously, the pedagogical intention is not to produce situations where students remain mired in despair, defensive, closed to dialogue and unable to see alternative and constructive forms of thought or action. On the contrary, it is hoped that they should move on to positions of critical hope. From the various student responses we analyzed, it would appear that most, but not all, of the students who participated in the project felt that they had undergone a valuable and productive learning experience.

\section{Final Thoughts About the Course}

A number of factors contributed to enactments of critical hope in this project. Bringing people together where they had the opportunity to interrogate concepts of community, self and identity and their associated feelings provided a platform for deep engagement about difference. The use of PLA techniques as an alternative and inclusive method allowed engagement that went beyond pure 'contact.' Performances by guest speakers stimulated spontaneous engagement and reactions. Students were able to share intimate details about their lives, providing challenging as well as more 
empathic engagements around humanity and the pain of their life stories. Telling their own stories provided students with the opportunity for reflexivity in relation to professional practice. Some students learnt what sharing personal details were like for 'clients.' Sharing their own experiences allowed them to see the 'other' as human beings rather than reified objects, thus connecting with each other's humanity (Bozalek 2011). Working in pre-structured groups across disciplines and institutions, with a final joint presentation in mind, forced students to engage with each other collaboratively. Furthermore, the tasks that was set for students were specifically designed to elicit discussions about difference and community.

There were also factors that engendered elements of despair on the part of the educators in their roles as curriculum designers. Despair was evident in some instances, for example, when the course appeared to consolidate prejudice or defensiveness for some students. In some cases preconceived ideas about difference between disciplines and institutions were also entrenched. However, it is important for educators to realize that the shift towards new ways of thinking may sometimes happen after the end of the course.

Despair on the part of the educators related to the disparities in marks. Stellenbosch students performed better than UWC students on the whole and in so doing symbolically contributed to maintaining preconceived views of who is competent. In addition, material differences among students were not altered; in fact, students' knowledge of their own material positions was highlighted when, for example, UWC students saw the elaborate student center (cafeteria/mall) at Stellenbosch University. Despite this engagement, some Stellenbosch students maintained patronizing and missionary attitudes. Similarly, many UWC students accepted the assumed competence of some Stellenbosch students by, for example, proposing that SU students do PowerPoint presentations for the group, thus re-enacting the stereotype of SU students as academically 'superior.' There were thus several aspects of the course that could be redesigned to ameliorate some of the elements which detracted from the success of the course, the principal one being its short duration. However, others are more systemic and contextual, and are beyond the scope of the course designers.

The course designers are currently working with the pedagogy of discomfort and the development of critical hope with higher educators across institutions, rather than working directly and exclusively with students. We see this shift in focus as a way of addressing sustainability of such endeavours in South African teaching and learning.

\section{Conclusion}

This chapter focuses on critical hope, both conceptually and practically, in the South African higher education context. Our discussion foregrounds the complexity of the development of critical hope through engaging in discomforting dialogues. We provide one possible way of conceptualizing critical hope as an iterative, ongoing 
process that has no end. The infinite nature of critical hope is crucial as it assumes that critical hope is a process associated with practices that are constantly reviewed and revised as a result of reflexivity and dialogue. We have used a concrete example of a teaching and learning project to illustrate the processes involved in designing a curriculum which contained opportunities for engaging in 'third space' dialogues across difference. The pedagogy of discomfort makes such a conceptualization of critical hope possible and serves as a guiding theoretical framework for our work on critical hope. In order to facilitate opportunities for the development of a critical hope, educators themselves need to be reflexive and continually vigilant regarding their own preparedness to reconfigure or reconstruct their own frameworks. This, as our project indicated, needs structured facilitation of dialoguing across difference, rather than leaving students to engage in open-ended conversations. 


\section{Bibliography}

Blackwell, D.M. (2010) 'Race Ethnicity and Education Sidelines and separate spaces: making education anti-racist for students of color', Race, Ethnicity and Education, 13(4): 473-94.

Boler, M. (1999) Feeling Power: Emotion and Education, New York: Routledge.

Boler, M. and Zembylas, M. (2003) 'Discomforting truths: The emotional terrain of understanding difference', in P. Trifonas (ed.) Pedagogies of difference: Rethinking education for social change, New York: Routledge-Falmer.

Bozalek, V. (2011) 'Acknowledging privilege through encounters with difference: Participatory learning and action techniques for decolonizing methodologies in Southern contexts', International Journal of Social Research Methodology, 4(6): 465-80.

Bozalek, V. and Biersteker, L. (2010) 'Exploring power and privilege using participatory learning and action techniques', Social Work Education, 29(5): $551-72$.

Bozalek, V. and Boughey, C. (2012) '(Mis)framing higher education', Social Policy and Administration, 46(6): 688-703.

Bozalek, V., Carolissen, R., Nicholls, L., Leibowitz, B., Swartz, L. and Rohleder, P. (2011) 'bell hooks and the enactment of emotion in teaching and learning across boundaries: A pedagogy of hope', South African Journal of Higher Education, 25(1): 157-67.

Carolissen, R. (2012) 'Student Experiences of the CSI module', in B. Leibowitz, L. Swartz, V. Bozalek, R. Carolissen, L. Nicholls and P. Rohleder (eds) Community, Self and Identity: Educating South African University Students for Citizenship, Cape Town: HSRC Press.

Chambers, R. (2007) 'From PRA to PLA and pluralism: Practice and theory', IDS Working Paper 286, University of Sussex: Institute of Development Studies, Brighton.

Education White Paper 3 (1997) A Programme for Higher Education Transformation. Online. Available HTTP: <http://www.info.gov.za/whitepapers/1997/educ3.pdf> (accessed 4 June 2009).

Durrheim, K. (2005) 'Socio-spatial practice and racial representations in a changing South Africa', South African Journal of Psychology, 35(3): 444-59.

Erasmus, Z.E. (2006) "Living the future now: "Race" and the challenges of transformation in higher education', South African Journal of Higher Education, 20(3): 413-25.

Fraser N. (2008) 'Reframing justice in a globalizing world', in K. Olson (ed.) Adding Insult to Injury: Nancy Fraser Debates Her Critics, London and New York: Verso.

Fraser N. (2009) Scales of justice. Reimagining political space in a globalizing world, New York: Columbia University Press.

Halabi, R. (2004) Israeli and Palestinian identities in dialogue: The school for peace approach, New Brunswick, NJ: Rutgers University Press. 
Jansen, J. (2009) Knowledge in the blood; Confronting race and the apartheid past, Cape Town: UCT Press

Jones, A. (2005) 'Talking Cure: the Desire for Dialogue', in M. Boler (ed.) Democratic Dialogue in Education: Troubling Speech, Disturbing Silence, New York: Peter Lang.

Leibowitz, B. (2012) 'Understanding the Challenges of the South African Higher Education Landscape', in B. Leibowitz, L. Swartz, V. Bozalek, R. Carolissen, L. Nicholls and P. Rohleder (eds) Community, Self and Identity: Educating South African University Students for Citizenship, Cape Town: HSRC Press.

Leibowitz, B., Bozalek, V., Rohleder, P., Carolissen, R. and Swartz, L. (2010.) “'Ah, but the whiteys love to talk about themselves": Discomfort as a pedagogy for change', Race, Ethnicity and Education, 13 (1): 83-100.

Leibowitz, B., Bozalek, V., Carolissen, R., Nicholls, L., Rohleder, P. and Swartz, L. (2012) 'Educating the Educators: Creation of a Powerful Learning Environment', in B. Leibowitz, L. Swartz, V. Bozalek, R. Carolissen, L. Nicholls and P. Rohleder (eds) Community, Self and Identity: Educating South African University Students for Citizenship, Cape Town: HSRC Press

Leonardo, Z. and Porter, R.K. (2010) 'Pedagogy of fear: Toward a Fanonian theory of "safety" in race dialogue', Race, Ethnicity and Education, 13(2): 139-57.

McKinney, C. (2004) “A little hard piece of glass in your shoe" - Understanding student resistance to critical literacy in post-apartheid South Africa', South African Linguistics and Applied Language Studies, 22(1+2): 63-73.

McKinney, C. (2007) 'Caught between the "old" and the "new"? Talking about "race" in a post-apartheid university classroom', Race, Ethnicity and Education, 10(2): $215^{-231 .}$

Ministerial Committee (2008) The Report of the Ministerial Committee on Transformation and Social Cohesion and the Elimination of Discrimination in Public Higher Education Institutions, Pretoria: Government Gazette.

Norton, B. (2000) Identity and Language Learning: Gender, Ethnicity and Educational Change, London: Pearson.

Sonn, C. (2008) 'Educating for anti-racism: Producing and reproducing race and power in a university classroom', Race, Ethnicity and Education, 11(2): 15566.

University of Stellenbosch, HOPE Project (no date) 'About the Hope Project'. Online. Available HTTP: <http://thehopeproject.co.za/hope/Pages/default.aspx> (accessed. 28 March 2103).

University of the Western cape website http://www.uwc.ac.za/searchcentre/pages/Results.aspx?k=hope (accessed 28 March 2013).

Walker, M., (2005) 'Rainbow nation or new racism? Theorizing race and identity formation in South African higher education', Race, Ethnicity and Education, 8(2): $129-46$.

Zembylas, M., (2007) Five Pedagogies, A Thousand Possibilities: Struggling for Hope and Transformation in Education, Rotterdam: Sense Publishers. 
Zembylas, M. (2008) The Politics of Trauma in Education, New York: Palgrave MacMillan.

Zembylas, M. (2010) 'Teachers' emotional experiences of growing diversity and multiculturalism in schools and the prospects of an ethic of discomfort', Teaching and Teachers: Theory and Practice, 16(6): 703-16.

Zembylas, M. and McGlynn, C. (2010) 'Discomforting pedagogies: emotional tensions, ethical dilemmas and transformative possibilities', British Educational Research Journal, 38(1): 41-59.

\footnotetext{
${ }^{\mathrm{i}}$ We use the South African terms for race found in most policy and census documents, i.e.

African, Coloured, Indian and White.

${ }^{i i}$ Pseudonym.

ii Pseudonym.
} 